\title{
Experimental Investigation and Computer Simulation of Gradient Zone Formation in WC-Ti(C,N)-TaC-NbC-Co Cemented Carbides
}

\author{
Weibin Zhang, Yingbiao Peng, Peng Zhou, Weimin Chen, Yong Du, Wen Xie, Guanghua Wen, and Shequan Wang
}

\author{
(Submitted August 30, 2012; in revised form December 30, 2012; published online March 2, 2013)
}

\begin{abstract}
The thermodynamic and diffusion databases for multi-component W-C-Co-Ti-Ta-Nb-N cemented carbides have been developed through a combination of experimental, theoretical and assessment work. Using the CALPHAD approach, the thermodynamic database has been established based on the literature information and experimental investigations. The diffusion database contains the atomic mobility parameters for different diffusing elements in liquid, which were calculated by a modified Sutherland equation. According to the present thermodynamic and diffusion databases, a gradiently sintered WC-Ti(C,N)-(Ta,Nb)C-Co cemented carbides has been designed and prepared. Scanning electron microscopy was employed to investigate the microstructure of the gradient zone, and electron probe microanalysis was used to determine the concentration profiles and distributions of the elements. The gradient zone formation of the cemented carbides was then simulated by DICTRA, and the simulation results show a good agreement with the experimental results.
\end{abstract}

Keywords cemented carbides, computer simulation, diffusion coefficient, gradient sintering, microstructure, thermodynamics

\section{Introduction}

Cemented carbides ${ }^{[1]}$ are hard and tough tool materials consisting of micrometer-sized carbides embedded in a metal binder phase, usually rich in Co. In order to increase the resistance of the cemented carbides to plastic deformation or behavior, gradient formers, in the form of carbides or carbonitrides with cubic structure, such as $\mathrm{TiC},(\mathrm{Ti}, \mathrm{W}) \mathrm{C}$, and $(\mathrm{Ti}, \mathrm{Ta}, \mathrm{Nb})(\mathrm{C}, \mathrm{N})$, have been introduced into $\mathrm{WC}-\mathrm{Co}$ matrix. Cemented carbides are widely used in industry as cutting tools, wear parts, and in machining and mining applications. ${ }^{[2]}$ In order to increase cutting performance of the cemented carbide inserts, the wear surface is usually coated with a thin layer of hard material such as TiC, TiN, TiCN, $\mathrm{Al}_{2} \mathrm{O}_{3}$ or their multilayers. ${ }^{[3]}$ Since the coating is often obtained by high-temperature chemical vapor deposition (CVD) technique, ${ }^{[4]}$ cracks would be introduced into the coating unavoidably due to the high deposition temperature and a large difference in thermal expansion coefficients between the coating and substrate. And the formed

Weibin Zhang, Yingbiao Peng, Peng Zhou, Weimin Chen, and Yong Du, State Key Laboratory of Powder Metallurgy, Central South University, Changsha 410083 Hunan, People's Republic of China; Wen Xie, Guanghua Wen, and Shequan Wang, Zhuzhou Cemented Carbide Cutting Tools Limited Company, Zhuzhou 412007 Hunan, People's Republic of China. Contact e-mail: yongducalphad@ gmail.com. cracks might easily propagate into the substrate to cause failure when coating tools are employed in metal machining. ${ }^{[5]}$ When gradient cemented carbides are used as the substrate of coated inserts, the surface gradient layer, which is free of cubic phases and enriched in binder phase, can prevent the crack formed in the coating from propagating into the bulk and causing failure, and hence extend the service lifetime of inserts. ${ }^{[6]}$

Many investigators have studied the gradient zone formation in the cemented carbides. ${ }^{[3,7-12]}$ The formation of the gradient zone is controlled by the thermodynamic properties of the system and the diffusion in the liquid binder. ${ }^{[3]}$ With the development of thermodynamic and diffusion databases, Thermo-Calc ${ }^{[13]}$ and DICTRA ${ }^{[14]}$ softwares have become very important techniques in simulating and understanding the gradient zone formation in the cemented carbides. Up to now, thermodynamic ${ }^{[15,16]}$ and diffusion $^{[3,10,17]}$ databases have been established and used to simulate the gradient sintering process.

With the development of cemented carbide industry in China, more and more companies in China have realized that the simulation can guide manufacturing process and reduce the cycle for the development of new cemented carbides significantly. Since the reported thermodynamic and diffusion databases for cemented carbide are for commercial purpose and thus not available in these publications, ${ }^{[3,10,15-17]}$ the development of these databases is of technical importance for us.

In this work, the establishment of thermodynamic and diffusion databases for multi-component W-C-Co-Ti-Ta-Nb$\mathrm{N}$ cemented carbides through a combination of experimental, theoretical and assessment work is briefly described. A cemented carbide WC-Ti(C,N)-(Ta,Nb)C-Co was then designed and sintered under vacuum. The microstructure of the gradient zone was investigated with scanning electron 
Table 1 Chemical composition of the investigated alloy (wt.\%)

\begin{tabular}{lllllll}
\hline Co & Ti & Ta & Nb & C & N & W \\
\hline 9 & 3 & 6 & 0.8 & 6.06 & 0.08 & Balance \\
\hline
\end{tabular}

microscopy (SEM). The concentration profiles and mappings of the elements were determined with electron probe microanalysis (EPMA). Subsequently, the gradient zone formation was simulated by means of DICTRA with currently established thermodynamic and diffusion databases. The simulation results were compared with the experimental results to demonstrate the application of the established databases.

\section{Experimental Procedure}

The alloys were prepared from a powder mixture of WC, $(\mathrm{Ti}, \mathrm{W}) \mathrm{C}, \mathrm{Ti}(\mathrm{C}, \mathrm{N}),(\mathrm{Ta}, \mathrm{Nb}) \mathrm{C}$ and metallic Co powder provided by Zhuzhou Cemented Carbide Cutting Tools Limited Company. The composition of the sintered material is given in Table 1. After milling and drying, the powders were pressed into cutting tool inserts. Samples were dewaxed and sintered in vacuum at $1723 \mathrm{~K}$ for $1 \mathrm{~h}$. After sintering, the samples were cut, embedded in resin and polished. SEM (Nova NanoSEM 230, USA) was employed to investigate the microstructure of the gradient zone, and EPMA (JXA-8230, JEOL, Japan) was used to determine the concentration profiles of the elements. The phase volume fraction distributions were calculated by the software ImageJ based on the SEM images.

\section{Modeling}

\subsection{Model for Diffusion}

Schwarzkopf et al. ${ }^{[8]}$ found that the formation of the gradient zone is controlled by the thermodynamic properties of the system and diffusion in the liquid binder phase. Due to the strong thermodynamic interaction between $\mathrm{N}$ and $\mathrm{Ti}$, $\mathrm{Ta}$ and $\mathrm{Nb}$, as $\mathrm{N}$ diffuses out from the material, Ti, Ta and $\mathrm{Nb}$ diffuse in the opposite direction. The thermodynamic coupling between $\mathrm{N}$ and $\mathrm{Ti}$, Ta and $\mathrm{Nb}$ may be expressed by the off-diagonal coefficients of the diffusion coefficient matrix $D_{k j}$ of the Fick-Onsager diffusion equation ${ }^{[10]}$

$J_{k}=-\sum_{j=1}^{n} D_{k j} \nabla C_{j}$

where $D_{k j}$ is the interdiffusion coefficient, $C_{j}$ is the concentration in mole per volume, and $\nabla$ denotes the divergence operator. The flux $J_{k}$ of species $k$ depends on the concentration gradients of all $n$ species.

For a substitutional solution phase, the interdiffusion coefficients in terms of the volume-fixed reference frame is given by the following expression ${ }^{[18,19]}$

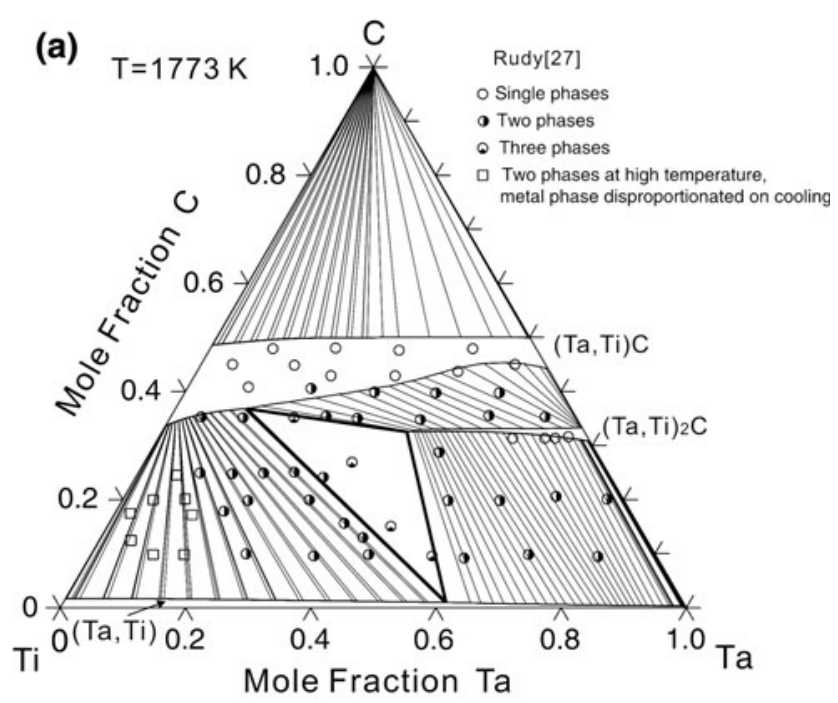

(b)

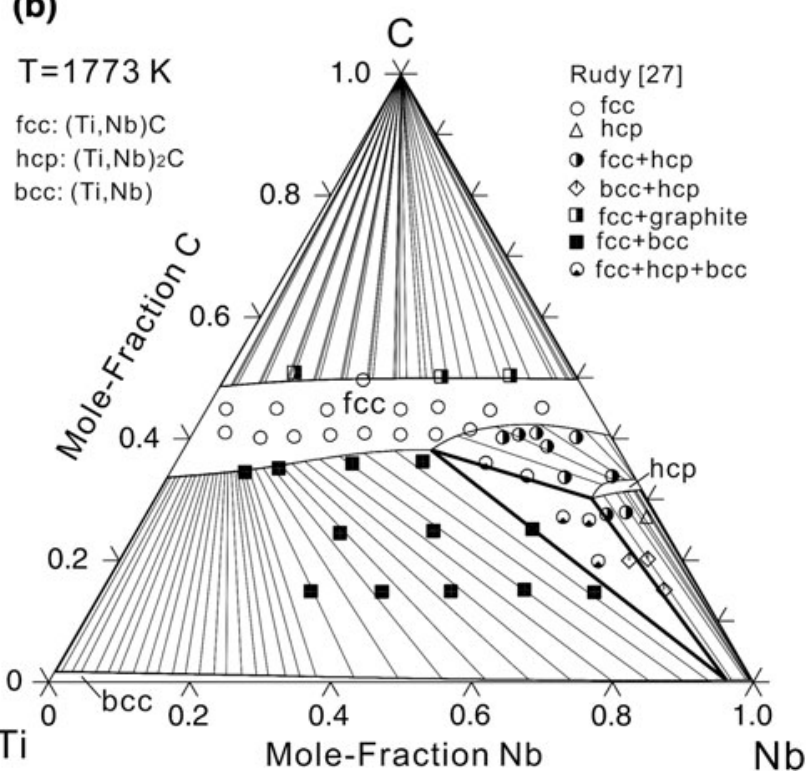

Fig. 1 Calculated isothermal section at $1773 \mathrm{~K}$ of (a) C-Ta-Ti and (b) C-Ti-Nb systems, compared with the experimental data $^{[27]}$

$\tilde{D}_{k j}^{n}=\sum_{i}\left(\delta_{i k}-x_{k}\right) \cdot x_{i} \cdot M_{i} \cdot\left(\frac{\partial \mu_{i}}{\partial x_{j}}-\frac{\partial \mu_{i}}{\partial x_{n}}\right)$

where $\delta_{i k}$ is the Kronecker delta $\left(\delta_{i k}=1\right.$ if $i=k$, otherwise $\left.\delta_{i k}=0\right) . x_{i}, \mu_{i}$, and $M_{i}$ are the mole fraction, chemical potential, and mobility of element $i$, respectively. The element $n$ is chosen as the dependent element. 


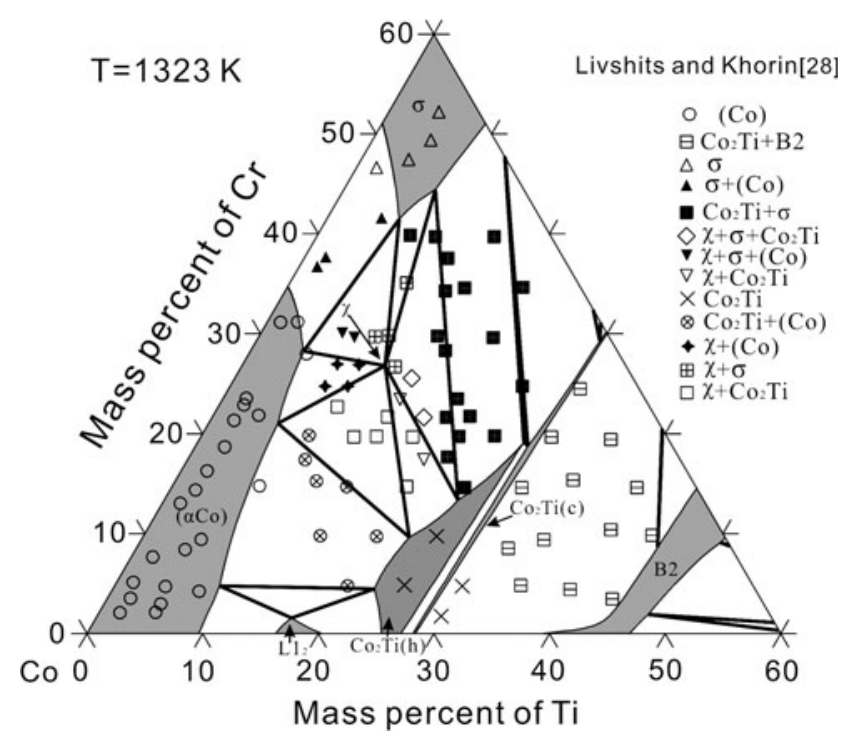

Fig. 2 Calculated isothermal section at $1323 \mathrm{~K}$ of the Co-Cr-Ti system, compared with the experimental data ${ }^{[28]}$

From the absolute reaction rate theory arguments, the mobility parameter $M_{i}$ may be divided into a frequency factor $M_{i}^{0}$ and an activation enthalpy $Q_{i}{ }^{[18,19]}$ Both $M_{i}^{0}$ and $Q_{i}$ are in general dependent on the composition, temperature, and pressure. According to the suggestion by Jönsson, ${ }^{[18]}$ the $M_{i}$ for fcc alloys is expressed by an equation of the following form,

$M_{i}=\exp \left(\frac{R T \ln M_{i}^{0}}{R T}\right) \exp \left(\frac{-Q_{i}}{R T}\right) \frac{1}{R T}$

where $R$ is the gas constant and $T$ the absolute temperature. Consequently, the composition dependence can be represented by a linear combination of the values at each endpoint of the composition space.

The simulation of gradient zone formation is based on the model for long-range diffusion occurring in a continuous matrix with dispersed phases. Due to the presence of dispersed phases (WC, carbides and carbonitrides), the diffusion is reduced in the matrix (the liquid binder phase). ${ }^{[20]}$ A so-called labyrinth factor $\lambda(f)$, where $f$ is the volume fraction of the matrix, was introduced to reduce the diffusion coefficient matrix:

$D_{k j_{\text {eff }}}^{n}=\lambda(f) D_{k j}^{n}$

Frykholm et al. ${ }^{[20]}$ found that the labyrinth factor $\lambda(f)=f$ yields a good correspondence between experiment and simulation. It can be found that the gradient zone width and binder content show a linear relationship. ${ }^{[20]}$ In this work the labyrinth factor $\lambda(f)=f$ was thus chosen.

\subsection{Brief Description of the Thermodynamic Database}

Thermodynamic calculations are very useful in alloy development and process design because they can easily predict phase relationships at different temperatures and calculate the concentrations during the sintering process. In
$\mathrm{TaN}$

WN

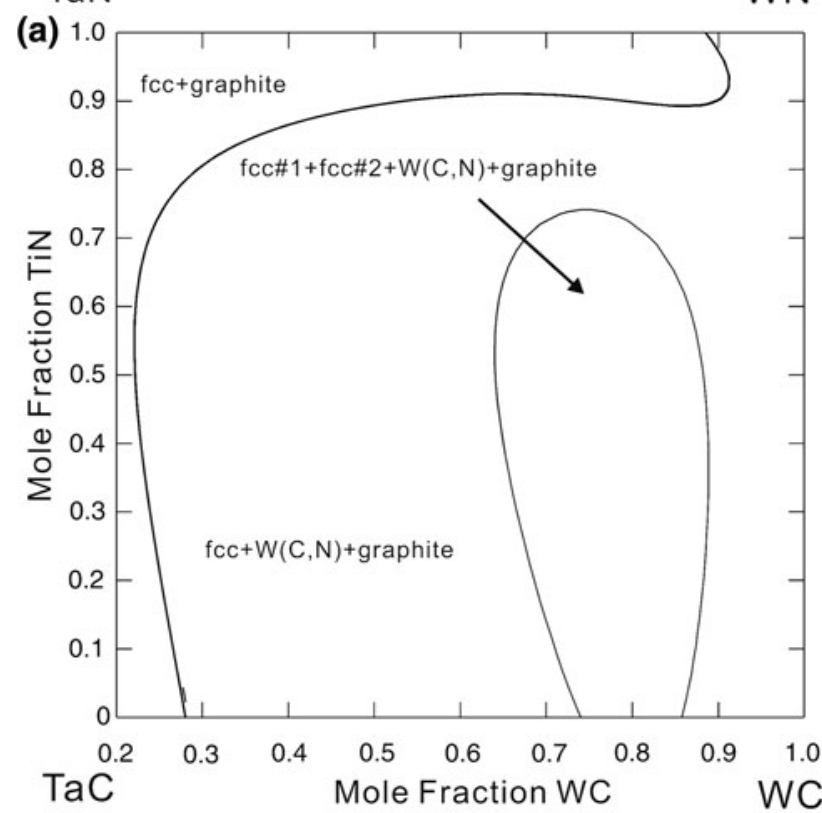

(b)

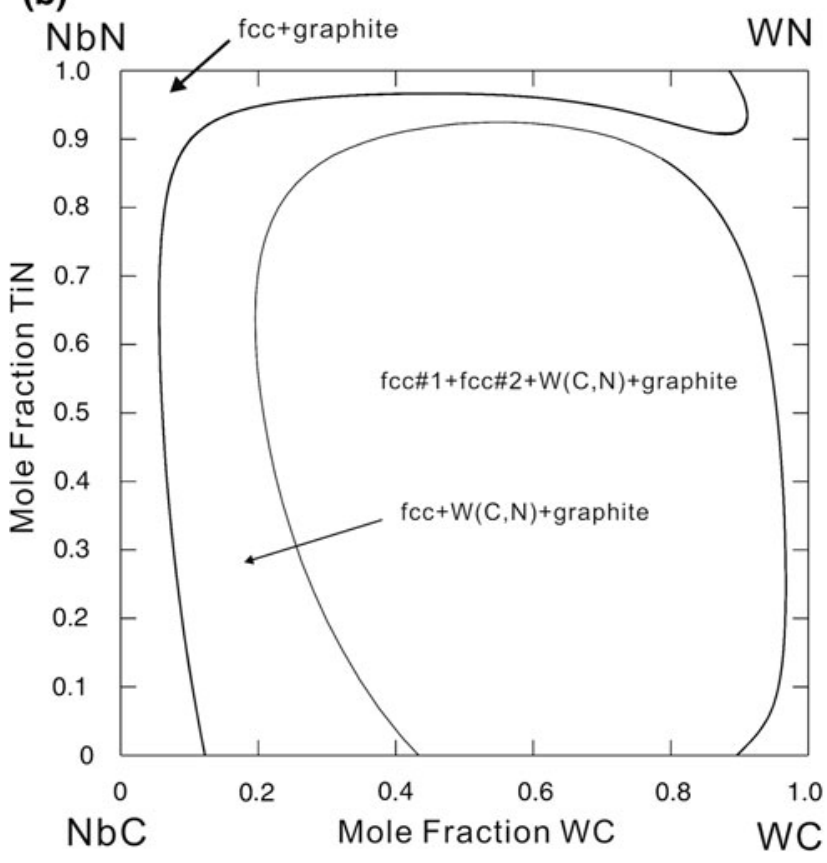

Fig. 3 Calculated projection at $1723 \mathrm{~K}$ with the carbon activity of one in the (a) C-W-Ta-N system; (b) C-W-Nb-N system

addition, application-related DICTRA simulations, such as the formation of the gradient zone, are performed based on the thermodynamic database in conjunction with the diffusion database. The accuracy of the simulations strongly depends on the quality of the two databases. Cemented carbides consist of WC, cubic carbides/carbonitrides and binder cubic $(\mathrm{Co})$. The undesirable graphite and eta $\left(\mathrm{M}_{6} \mathrm{C}\right.$ or $\mathrm{M}_{12} \mathrm{C}$ ) phases often appear in cemented carbides, and the carbon content in cemented carbides should be carefully 

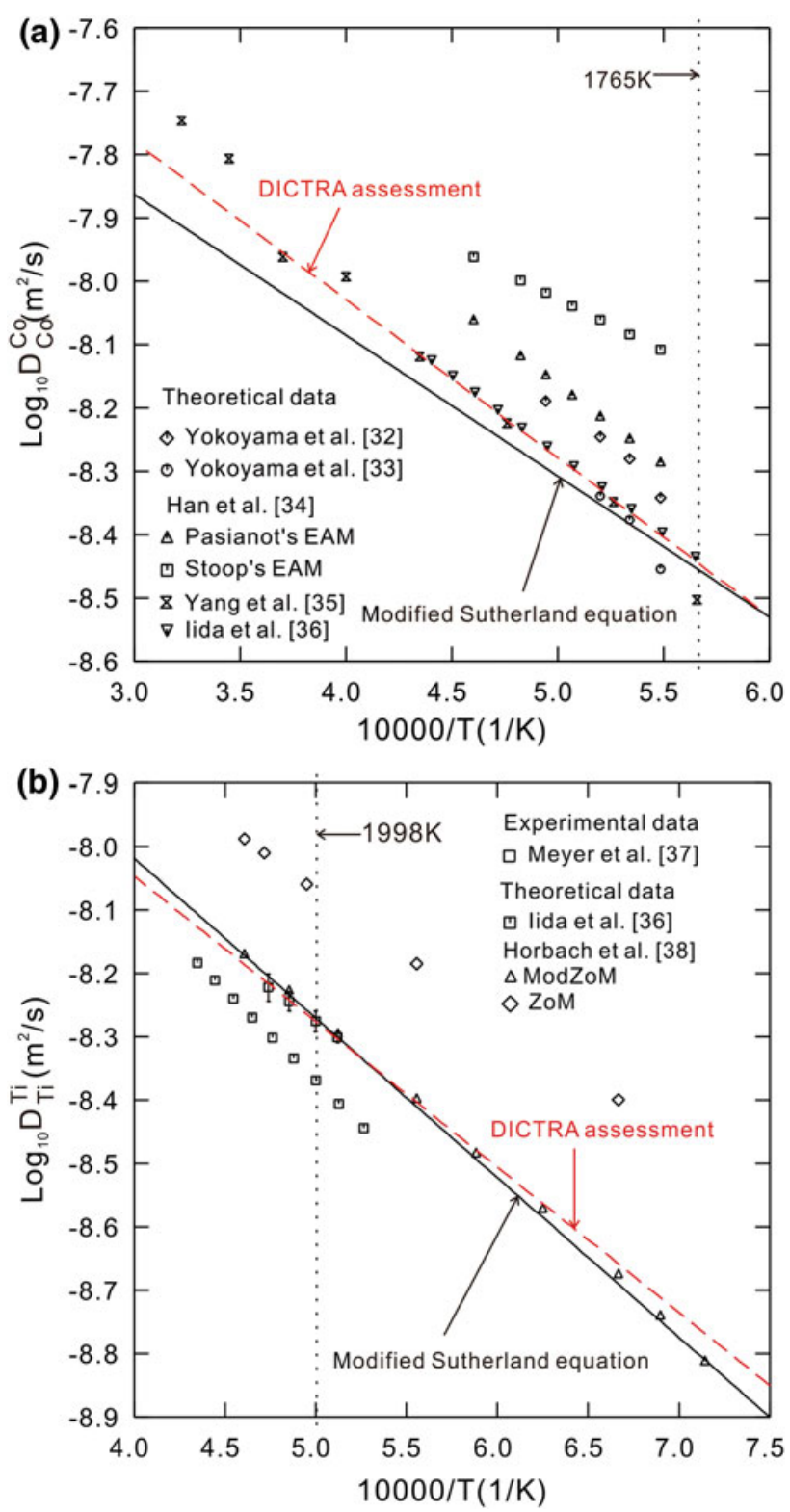

Fig. 4 Calculated self-diffusion coefficients for pure liquid (a) Co and (b) Ti, compared with the corresponding data available in the literature ${ }^{[32-38]}$

controlled to avoid the formation of these phases. As a result, the above five phases among the numerous phases in the systems are the main focus during the modeling.

Using the CALPHAD method, ${ }^{[21]}$ the establishment of the thermodynamic database is based on previous thermodynamic descriptions for all of the binary systems and most of the ternary systems reported in the literature. Some of the ternary systems are assessed according to experimental data including the $\mathrm{C}-\mathrm{Cr}-\mathrm{Ta} a,{ }^{[22]} \mathrm{C}-\mathrm{Ta}-\mathrm{Ti},{ }^{[23]} \mathrm{C}-\mathrm{Ti}^{-\mathrm{Nb}^{[24]}}$ and $\mathrm{Co}-$ $\mathrm{Cr}-\mathrm{Ti}^{[25]}$ systems. The description on the established thermodynamic database is given elsewhere. ${ }^{[26]}$ Figure 1 presents the calculated isothermal section at $1773 \mathrm{~K}$ of

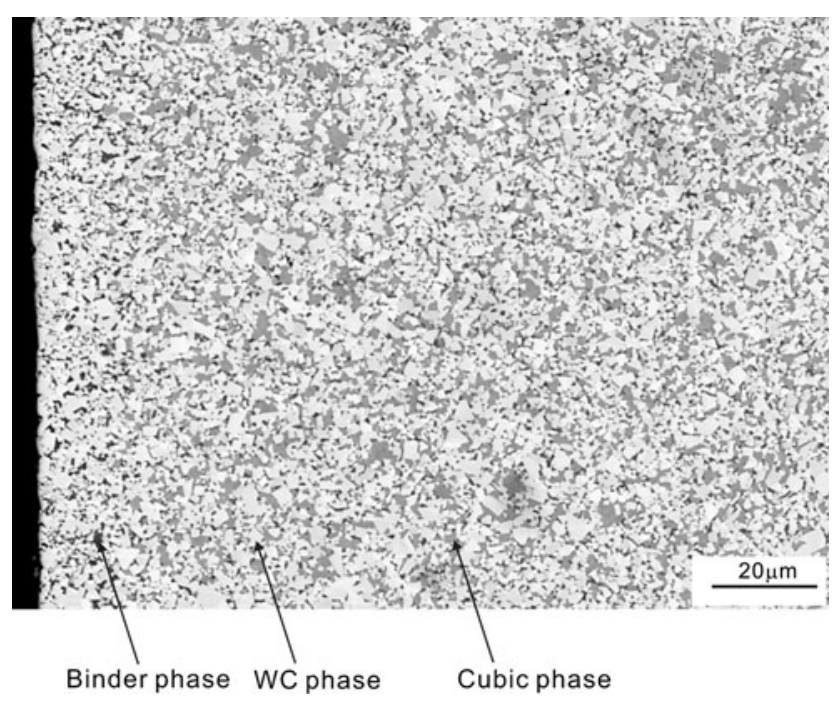

Fig. 5 SEM micrograph of the cross section of the cemented carbide WC-Ti(C,N)-(Ta,Nb)C-Co after sintering in vacuum at $1723 \mathrm{~K}$ for $1 \mathrm{~h}$

(a) $\mathrm{C}-\mathrm{Ta}-\mathrm{Ti}$ and (b) $\mathrm{C}-\mathrm{Ti}-\mathrm{Nb}$ systems, compared with the experimental data. ${ }^{[27]}$ As can be seen, a wide band of continuous solid solution is formed between $\mathrm{fcc} \mathrm{TiC}$ and $\mathrm{TaC} / \mathrm{NbC}$ carbides. For the $\mathrm{Co}-\mathrm{Cr}-\mathrm{Ti}$ system, all the experimental data in the whole composition and temperature ranges are assessed. Figure 2 shows the calculated isothermal section at $1323 \mathrm{~K}$ of the $\mathrm{Co}-\mathrm{Cr}-\mathrm{Ti}$ system, compared with the experimental data, ${ }^{[28]}$ which accurately describes the huge solubility of $\mathrm{Ti}$ and $\mathrm{Cr}$ in Co phase. Based on the presently established thermodynamic database, calculations on the solubility of WC in cubic carbide and the miscibility gap in the cubic carbide are performed in the quaternary $\mathrm{C}-\mathrm{W}-\mathrm{Ta}-\mathrm{N}$ and $\mathrm{C}-\mathrm{W}-\mathrm{Nb}-\mathrm{N}$ systems. These calculations are shown in Fig. 3.

\subsection{Brief Description of the Diffusion Database}

As for the diffusion database, due to the lack of detailed information on liquid diffusion, Ekroth et al. ${ }^{[3]}$ and Frykholm et al. ${ }^{[10]}$ assumed that all elements $(\mathrm{Co}, \mathrm{Ti}, \mathrm{W}, \mathrm{Ta}, \mathrm{Nb}$, $\mathrm{C}$ and $\mathrm{N}$ ) had the same mobility in the liquid. Garcia et al. ${ }^{[17]}$ assumed that the mobility of the metallic elements (W, Co, Ti, Ta and $\mathrm{Nb}$ ) was two times slower than the mobility of light non-metallic elements ( $\mathrm{C}$ and $\mathrm{N})$ by comparing the measured graded layer thicknesses with the simulation ones. However, the above assumptions are far away from reality. Consequently, an effective method is needed to predict diffusivity in liquid. Recently, Chen et al. ${ }^{[29]}$ in our group derived a modified Sutherland equation, which is coupled with Kaptay's viscosity equation $^{[30]}$ and Proptopapas's temperature-dependent effective diameter ${ }^{[31]}$ to predict the temperature-dependence diffusivity in liquid metals.

$D_{B B}=D_{B B}^{0} \cdot \exp \left(-\frac{Q_{B B}}{R T}\right)$ 

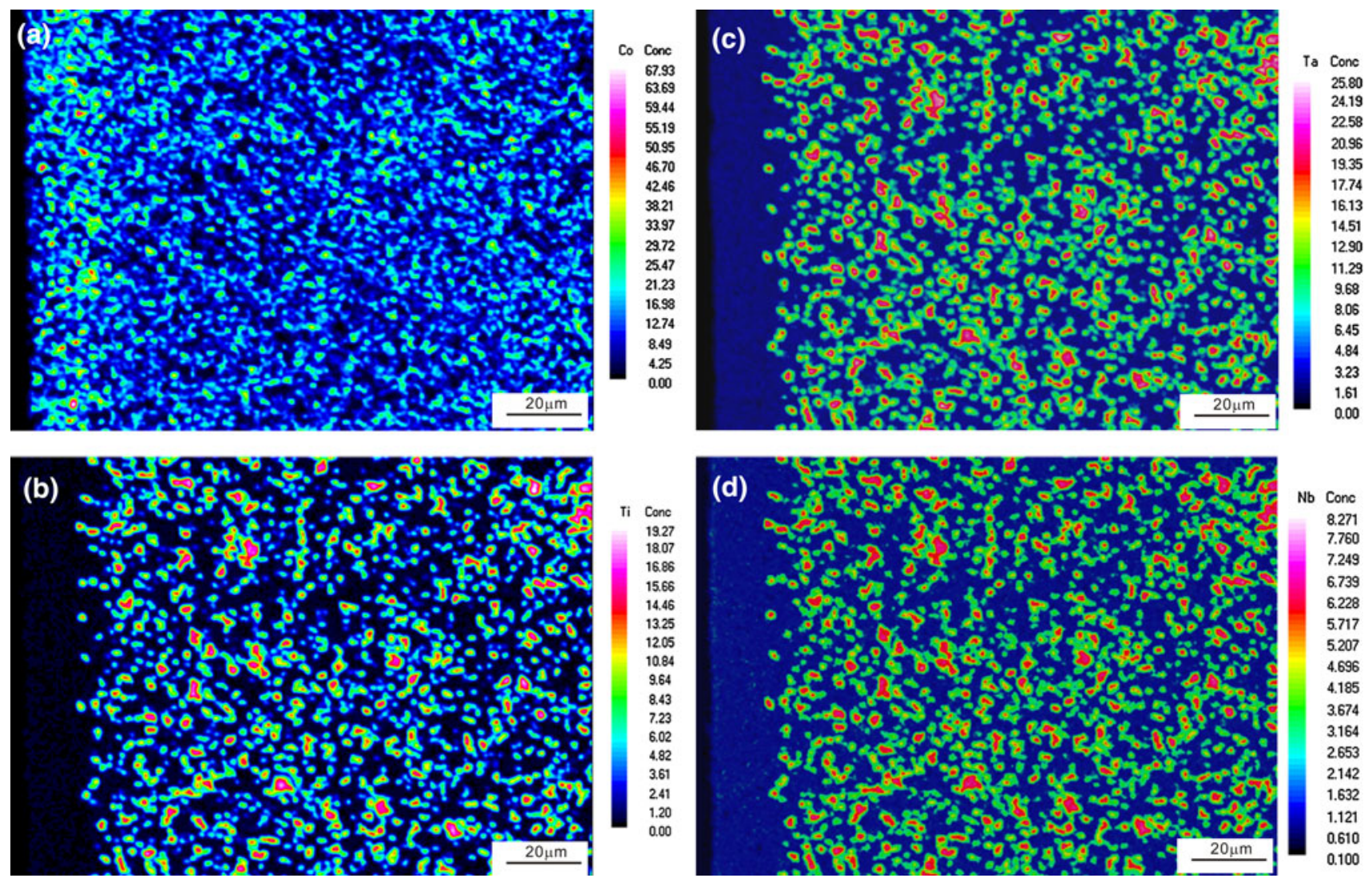

Fig. 6 The distribution of the elements (a) Co, (b) Ti, (c) Ta and (d) Nb in the gradient zone of the cemented carbide WC-Ti(C,N)$(\mathrm{Ta}, \mathrm{Nb}) \mathrm{C}-\mathrm{Co}$

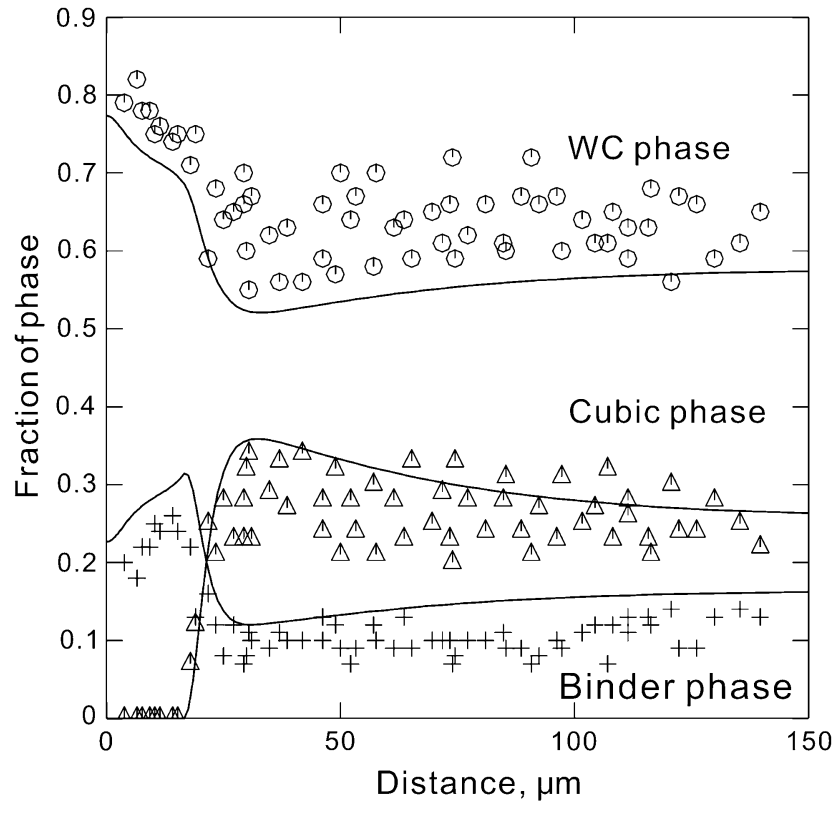

Fig. 7 Experimental and calculated phase fractions in the cemented carbide $\mathrm{WC}-\mathrm{Ti}(\mathrm{C}, \mathrm{N})-(\mathrm{Ta}, \mathrm{Nb}) \mathrm{C}-\mathrm{Co}$ after sintering for $1 \mathrm{~h}$ at $1723 \mathrm{~K}$ in a $\mathrm{N}$-free atmosphere with

$D_{B B}{ }^{0}=\frac{3.3737 \times 10^{-16} V_{B}^{1 / 3} \sqrt{T_{B}^{m}}}{C_{1} M_{B}^{1 / 2}}$

$Q_{B B}=\left(C_{2}+\frac{1}{1.776}\right) \cdot R T_{B}^{m}$

where $T$ is the absolute temperature, and $M_{i}, V_{i}$ and $T_{i}^{m}$ are the atomic mass, the absolute molar volume and the melting point under one atmospheric pressure of the given metal $i$, respectively. The constants $C_{1}$ and $C_{2}$ were found to be $(1.80 \pm 0.39) \times 10^{-8}\left(\mathrm{~J} \cdot \mathrm{K}^{-1} \cdot \mathrm{mol}^{-1 / 3}\right)^{1 / 2}$ and $(2.34 \pm 0.20)$, respectively.

The self-diffusivity parameters of $\mathrm{Co}$ and $\mathrm{Ti}$ in metallic liquid phase were calculated by the modified Sutherland equation and optimized by DICTRA software, respectively. The comparison of the self-diffusivity parameters for Co and $\mathrm{Ti}$ in liquid via the two methods is used to verify the accuracy of the modified equation. There exist some theoretical and experimental self-diffusion coefficients for $\mathrm{Co}$ and $\mathrm{Ti}$ in liquid state. Using the pair and triplet correlation entropies, Yokoyama et al. ${ }^{[32,33]}$ calculated the self-diffusion coefficient based on Dzugutov's scaling law. 

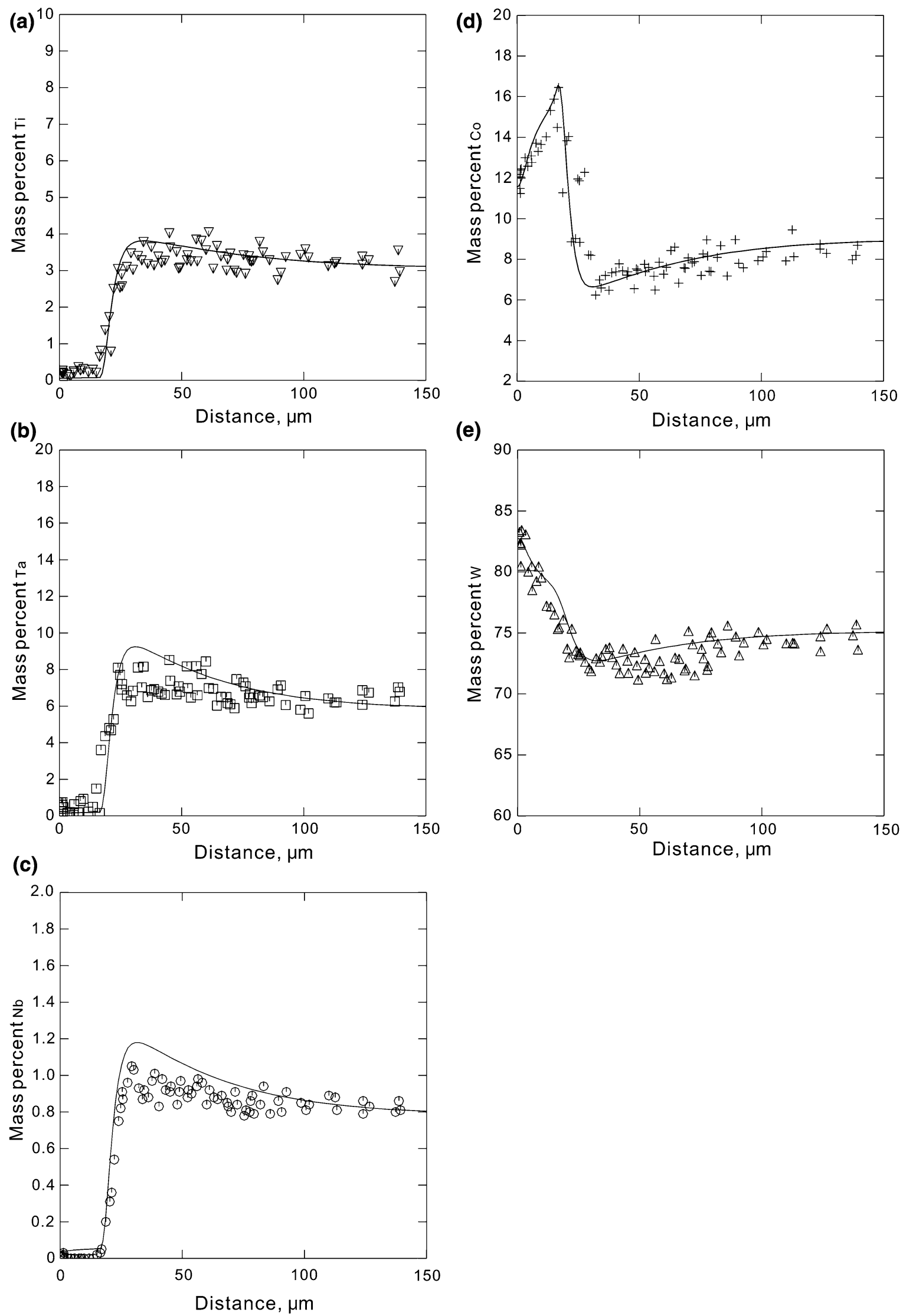
4 Fig. 8 Experimental and calculated elemental concentration profiles for (a) $\mathrm{Ti}$, (b) $\mathrm{Ta}$, (c) $\mathrm{Nb}$, (d) Co and (e) $\mathrm{W}$ in the cemented carbide $\mathrm{WC}-\mathrm{Ti}(\mathrm{C}, \mathrm{N})-(\mathrm{Ta}, \mathrm{Nb}) \mathrm{C}-\mathrm{Co}$ after sintering for $1 \mathrm{~h}$ at $1723 \mathrm{~K}$ in a $\mathrm{N}$-free atmosphere

By means of molecular dynamics (MD) simulation with Pasianot's and Stoop's embedded-atom-method (EAM) potentials, Han et al. ${ }^{[4]}$ calculated the self-diffusion coefficient of liquid cobalt at temperature above and below the melting temperature. Employing the MD method with the semi-empirical potentials derived from the second-moment approximation to the tight binding method (TBM-SMA), Yang et al. ${ }^{[35]}$ calculated the self-diffusivity of $\mathrm{Co}$ in liquid Co in the temperature range from 1768 to $3100 \mathrm{~K}$. Iida et al. ${ }^{[36]}$ predicted the self-diffusivity in liquid Co and Ti by combining the modified Stokes-Einstein formula with the Iida's model. Meyer et al. ${ }^{[37]}$ and Horbach et al. ${ }^{[38]}$ measured the self-diffusion coefficients in liquid $\mathrm{Ti}$ by means of incoherent QNS in the temperature range of 1953-2110 K. Only theoretically predicted self-diffusion coefficients exist for liquid Co. The theoretically predicted Co self-diffusion coefficients from different sources ${ }^{[32-36]}$ exhibit a relatively large scatter. Considering the fact that all the reported selfdiffusion coefficients in liquid Co except Han et al.' ${ }^{\left[{ }^{[34]}\right.}$ agree with each other to a certain degree, they are used to assess the atomic mobility for pure Co in the present work. The selfdiffusion coefficients in liquid Ti have been measured by Meyer et al. ${ }^{[37]}$ and Horbach et al. ${ }^{[38]}$ and utilized to evaluate the atomic mobility for pure Ti. While those theoretically predicted ones ${ }^{[36]}$ are only used for a comparison with the finally obtained atomic mobilities. Figure 4(a) and (b) presents the calculated self-diffusion coefficients for pure liquid $\mathrm{Co}$ and $\mathrm{Ti}$, compared with the corresponding data available in the literature. ${ }^{[32-38]}$ The solid lines refer to the diffusion coefficients from the modified Sutherland equation. The dashed lines refer to the diffusion coefficients according to DICTRA assessment. The calculated self-diffusivity of Co by the modified Sutherland equation agrees reasonably with the theoretically predicted data by Yang et al. ${ }^{[35]}$ and Iida et al ${ }^{[36]}$ It is clearly shown that the measured self-diffusivities of $\mathrm{Ti}^{[37,38]}$ can be well described by the modified Sutherland equation. The results show that the modified Sutherland equation can be used to calculate the diffusivity in liquid metals when there is no experimental or theoretical information on the diffusivity in liquid. The presently established diffusion database is given elsewhere. ${ }^{[39]}$

\section{Results and Discussion}

\subsection{Microstructure and Elemental Distributions}

Figure 5 shows SEM micrograph of the cross section of the cemented carbide after sintering under vacuum at $1723 \mathrm{~K}$ for $1 \mathrm{~h}$. In the micrograph, bright contrast is WC phase, grey is cubic phase, and dark is Co-rich binder phase. It is obvious that the near-surface of the alloy has formed the gradient zone which is enriched in binder phase and depleted in cubic carbides. The distributions of the elements $\mathrm{Co}, \mathrm{Ti}, \mathrm{Ta}$ and $\mathrm{Nb}$ on the gradient zone of the cemented carbide are shown in Fig. 6. As seen from Fig. 6, the nearsurface of the gradient zone is rich in Co, and inside the surface zone there is a depletion of Co. It is also shown that the elements $\mathrm{Ti}, \mathrm{Ta}$ and $\mathrm{Nb}$ exist mainly in the cubic phase. The distributions of the elements $\mathrm{Ti}, \mathrm{Ta}$ and $\mathrm{Nb}$ result from the similar diffusion behavior. According to the color contrast, some of the cubic phase has formed core-rim structure consisting of a $(\mathrm{Ti}, \mathrm{W}, \mathrm{Ta}, \mathrm{Nb})(\mathrm{C}, \mathrm{N})$ phase. From the core to the rim, the content of the elements $\mathrm{Ti}, \mathrm{Ta}$ and $\mathrm{Nb}$ decreases.

\subsection{Diffusion Simulation}

The thermodynamic ${ }^{[26]}$ and diffusion ${ }^{[39]}$ databases for cemented carbides described above have been established by experimental, theoretical and assessment methods. Although the databases ${ }^{[26,39]}$ can be used to perform thermodynamic and diffusivity calculations, the simulation of gradient zone formation by DICTRA is an indication to show the application of the established databases.

Figure 7 shows the measured and calculated phase fractions in the cemented carbide after sintering for $1 \mathrm{~h}$ at $1723 \mathrm{~K}$ in a $\mathrm{N}$-free atmosphere. As can be seen in Fig. 7, the nearsurface zone is free of cubic phase since the outward diffusion of $\mathrm{N}$ causes the inward diffusion of Ti. Inside the surface zone, the cubic phase appeared rapidly and reached a maximum. Because the inward diffusion of Ti leaves a lot of holes which could be fulfilled through the outward diffusion of $\mathrm{Co}$, the binder phase is enriched in the near-surface zone. The WC phase has the highest content in the near-surface zone which is free from cubic phase. Subsequently, there is a decrease in WC phase because of the formation of the cubic phase. The presently calculated results are in good accordance with the presently experimental data. The measured thickness of the gradient zone is about $16 \mu \mathrm{m}$.

Figures 8(a)-(e) illustrates the experimental and calculated elemental concentration profiles for $\mathrm{Ti}, \mathrm{Ta}, \mathrm{Nb}, \mathrm{Co}$ and $\mathrm{W}$ in the cemented carbide after sintering for $1 \mathrm{~h}$ at $1723 \mathrm{~K}$ in a $\mathrm{N}$-free atmosphere. This result indicates that the elemental concentration profiles for $\mathrm{Ti}, \mathrm{Ta}$ and $\mathrm{Nb}$ show the similar behavior. The content of $\mathrm{Ti}, \mathrm{Ta}$ and $\mathrm{Nb}$ is free in the nearsurface zone and enrichment inside the surface zone. At the near-surface zone, the content of Co increases sharply and reached a maximum value. Beneath the near-surface zone, a decrease of $\mathrm{Co}$ is observed, which leads to the minimum value. Above this minimum value, the content of Co increases slowly to its bulk value. The $\mathrm{W}$ curve has a maximum just at the surface of the cemented carbides. Comparing the concentration profile of $\mathrm{W}$ with the volume profile for $\mathrm{WC}$ phase, it can be seen that both curves show the same behavior. As can be seen in Fig. 8(a)-(e), the presently obtained thermodynamic and diffusion databases can reasonably reproduce most of the experimental concentration profiles.

\section{Conclusion}

A gradiently sintered $\mathrm{WC}-\mathrm{Ti}(\mathrm{C}, \mathrm{N})-(\mathrm{Ta}, \mathrm{Nb}) \mathrm{C}-\mathrm{Co}$ cemented carbides has been prepared by sintering at $1723 \mathrm{~K}$ for $1 \mathrm{~h}$ in a $\mathrm{N}$-free atmosphere. The microstructure of the 
gradient zone has been investigated with SEM, and the concentration profiles and distributions of the elements has been determined with EPMA. In order to accurately simulate the gradient zone formation of the cemented carbides by DICTRA, thermodynamic and diffusion databases for multi-component W-C-Co-Ti-Ta-Nb-N cemented carbides have been developed through a combination of experimental, theoretical and assessment work. Comparisons between the calculated and measured results show that most of the experimental data can be well reproduced by the presently obtained databases.

\section{Acknowledgments}

The financial support from the Creative Research Group of National Natural Science Foundation of China (Grant No. 51021063) and Zhuzhou cemented carbide cutting tools limited company of China is acknowledged. The ThermoCalc Software AB in Sweden is gratefully acknowledged for the provision of Thermo-Calc software.

\section{References}

1. H.O. Andrén, Microstructures of Cemented Carbonitrides, Mater. Des., 2001, 22(6), p 491-498

2. M. Rosso, G. Porto, and A. Geminiani, Studies of Graded Cemented Carbides Components, Int. J. Refract. Met. Hard Mater., 1999, 17, p 187-192

3. M. Ekroth, R. Frykholm, M. Lindholm, H.O. Andrén, and J. Ågren, Gradient Zones in WC-Ti (C, N)-Co-Based Cemented Carbides: Experimental Study and Computer Simulations, Acta Mater., 2000, 48(9), p 2177-2185

4. M. Fitzsimmons and V.K. Sari, Development of CVD WC-Co Coatings, Surf. Coat. Technol., 2001, 137, p 158-163

5. L. Chen, E.X. Wu, F. Yin, and J. Li, Effects of Gradient Structure on the Microstructures and Properties of Coated Cemented Carbides, J. Univ. Sci. Technol. B., 2006, 13(4), p 363-367

6. T.E. Yang, J. Xiong, L. Sun, Z.X. Guo, and D. Cao, Effect of Nitrogen Introduction Methods on the Microstructure and Properties of Gradient Cemented Carbides, Int. J. Miner. Metal. Mater., 2011, 18(6), p 709-716

7. H. Suzuki, K. Hayashi, and Y. Taniguchi, The Beta-Free Layer Formed Near the Surface of Vacuum-Sintered WC-beta-Co alloys Containing Nitrogen, Trans. Jpn. Inst. Met., 1981, 22, p 758-764

8. M. Schwarzkopf, H.E. Exner, H.F. Fischmeister, and W. Schintlmeister, Kinetics of Compositional Modification of (W, Ti)C-WC-Co Alloy Surfaces, Mater. Sci. Eng. A, 1988, 105(106), p 225-231

9. P. Gustafson and Å. Östlund, Binder-Phase Enrichment by Dissolution of Cubic Carbides, Int. J. Refract. Met. Hard Mater., 1994, 12(3), p 129-136

10. R. Frykholm, M. Ekroth, B. Jönsson, H.O. Andrén, and J. Ågren, Effect of Cubic Phase Composition on Gradient Zone Formation in Cemented Carbides, Int. J. Refract. Met. Hard Mater., 2001, 19(4), p 527-538

11. J. Garcia, Investigations on Kinetics of Formation of fcc-Free Surface Layers on Cemented Carbides with Fe-Ni-Co Binders, Int. J. Refract. Met. Hard Mater., 2011, 29, p 306-311
12. J. Garcia and O. Prat, Experimental Investigations and DICTRA Simulations on Formation of Diffusion-Controlled fcc-Rich Surface Layers on Cemented Carbides, Appl. Surf. Sci., 2011, 257(21), p 8894-8900

13. B. Sundman, B. Jönsson, and J.O. Andersson, The ThermoCalc Databank System, CALPHAD, 1985, 9(2), p 153-190

14. J.O. Andersson, L. Hoeglund, B. Jönsson and J. Ågren, Computer Simulation of Multi-Component Diffusional Transformations in Steel, Fundam. Appl. Ternary Diffus., Proc. Int. Symp., 1990, p 153-163

15. K. Frisk, L. Dumitrescu, M. Ekroth, B. Jönsson, O. Kruse, and B. Sundman, Development of a Database for Cemented Carbides: Thermodynamic Modeling and Experiments, J. Phase Equilib. Diffus., 2001, 22(6), p 645-655

16. M. Ekroth, K. Frisk, B. Jönsson, and L.F.S. Dumitrescu, Development of a Thermodynamic Database for Cemented Carbides for Design and Processing Simulations, Metall. Mater. Trans. B, 2000, 31B, p 615-619

17. J. Garcia, G. Lindwall, O. Prat, and K. Frisk, Kinetics of Formation of Graded Layers On Cemented Carbides: Experimental Investigations and DICTRA Simulations, Int. J. Refract. Met. Hard Mater., 2011, 29, p 256-259

18. B. Jönsson, Assessment of the Mobility of Carbon in fcc C-CrFe-Ni Alloys, Z. Metallkd., 1994, 85(7), p 502-509

19. J.O. Andersson and J. Ågren, Models for Numerical Treatment of Multi-Component Diffusion in Simple Phases, J. Appl. Phys., 1992, 72(4), p 1350-1355

20. R. Frykholm, M. Ekroth, B. Jönsson, J. Ågren, and H.O. Andrén, A New Labyrinth Factor for Modelling the Effect of Binder Volume Fraction on Gradient Sintering of Cemented Carbides, Acta Mater, 2003, 51, p 1115-1121

21. L. Kaufman and H. Bernstein, Computer Calculations of Phase Diagrams, Academic Press, New York, NY, 1970

22. C.S. Sha, M.J. Bu, H.H. Xu, Y. Du, S.Q. Wang, and G.H. Wen, A Thermodynamic Modeling of the C-Cr-Ta Ternary System, J. Alloy Compd., 2011, 509, p 5996-6003

23. Y.B. Peng, Y. Du, P. Zhou, and K.K. Chang, Thermodynamic Evaluation of the C-Ta-Ti System and Extrapolation to the C-Ta-Ti-N System, Int. J. Refract. Met. Hard Mater., under review, 2013

24. Y.B. Peng, P. Zhou, Y. Du, S.Q Wang, G.H Wen, W. Xie, and D. Živković, Thermodynamic Modeling of the C-Nb-Ti System, CALPHAD, accepted, 2013

25. P. Zhou, Y. Du, and Y.B. Peng, A Thermodynamic Description of the Co-Cr-Ti Ternary System over the Entire Composition and Composition Ranges, CALPHAD, accepted, 2013

26. www.imdpm.net/CSUTDCC1.htm. Accessed December 2012

27. E. Rudy, Part I. Phase Diagrams of the Systems TitaniumNiobium-Carbon, Titanium-Tantalum-Carbon, and TitaniumMolybdenum-Carbon, Mater. Res. Lab., Aerojet-Gen. Corp., Sacramento, CA, USA Tech. Rep. AFML-TR-69-117, 1970

28. B.G. Livshits and Y.D. Khorin, Study of the Equilibrium Phase Diagram of the System Co-Cr-Ti, Zh. Neorg. Khim., 1958, 3, p 685-693

29. W.M. Chen, L.J. Zhang, and Y. Du, A Modified Sutherland Equation for Obtaining Diffusivities in Liquid and Its Effect on Microstructure Simulation of WC-Ti(C,N)-Co Gradient Cemented Carbides, Metall. Mater. Trans. A, under review, 2013

30. G. Kaptay, A Unified Equation for the Viscosity of Pure Liquid Metals, Z. Metallkd., 2005, 96(1), p 24-31

31. P. Protopapas, H.C. Andersen, and N.A.D. Parlee, Theory of Transport in Liquid Metals. I. Calculation of Self-Diffusion Coefficients, J. Chem. Phys., 1973, 59(1), p 15-25 
32. I. Yokoyama, Self-Diffusion Coefficient and Its Relation to Properties of Liquid Metals: A Hard-Sphere Description, Physica B, 1999, 271, p 230-234

33. I. Yokoyama and T. Arai, Correlation Entropy and Its Relation to Properties of Liquid Iron, Cobalt and Nickel, J. Non-Cryst. Solids, 2001, 293-295, p 806-811

34. X.J. Han, J.Z. Wang, M. Chen, and Z.Y. Guo, Molecular Dynamics Simulation of Thermophysical Properties of Undercooled Liquid Cobalt, J. Phys.: Condens. Matter, 2004, 16, p 2565-2574

35. S. Yang, X. Su, J. Wang, F. Yin, and N. Tang, Molecular Dynamics Analysis of Temperature Dependence of Liquid Metal Diffusivity, Metall. Mater. Trans. A, 2009, 40A, p 3108-3116
36. T. Iida, R. Guthrie, and N. Tripathi, A Model for Accurate Predictions of Self-Diffusivities in Liquid Metals, Semimetals, and Semiconductors, Metall. Mater. Trans. B, 2006, 37B, p 559-564

37. A. Meyer, J. Horbach, O. Heinen, D. Holland-Moritz, and T. Unruh, Self Diffusion in Liquid Titanium: Quasielastic Neutron Scattering and Molecular Dynamics Simulation, Defect. Diffus. Forum, 2009, 289-292, p 609-614

38. J. Horbach, R.E. Rozas, T. Unruh, and A. Meyer, Improvement of Computer Simulation Models for Metallic Melts Via Quasielastic Neutron Scattering: A Case Study of Liquid Titanium, Phys. Rev. B, 2009, 80, p 212203

39. www.imdpm.net/CSUDDCC1.htm. Accessed December 2012 